DE

M E D I C I N A

T R O P I C A L

$\mathrm{DE}$

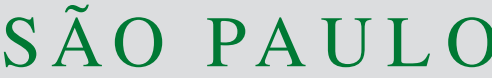

JOURNAL OF THE SÃO PAULO INSTITUTE OF TROPICAL MEDICINE

(1) Universidade de São Paulo, Instituto de Medicina Tropical de São Paulo, São Paulo, Brazil

(2) Universidade de São Paulo, Instituto de Ciências Biomédicas, Departamento de Parasitologia, São Paulo, Brazil

(3) Instituto Emilio Ribas de São Paulo, São Paulo, Brazil

(4) Universidade Federal de São Paulo, Escola Paulista de Medicina, Departamento de Microbiologia, Imunologia e

Parasitologia, São Paulo, Brazil

(5) Universidade de São Paulo, Faculdade de Medicina, Departamento de Medicina Preventiva, São Paulo, Brazil

Correspondence to: Norival Kesper. Instituto de Medicina Tropical de São Paulo, Universidade de São Paulo, Av. Dr. Enéas de Carvalho Aguiar, 470, CEP 05403000 , São Paulo, SP, Brazil.

Tel: +55 11 3061-7015.

E-mail: nkesper@usp.br

Received: 19 August 2016

Accepted: 07 December 2016

\section{Leptomonas seymouri and Crithidia fasciculata exoantigens can discriminate human cases of visceral leishmaniasis from American tegumentary leishmaniasis ones}

\author{
Norival Kesper ${ }^{1}$, Marta Maria G. Teixeira ${ }^{2}$, José Angelo L. Lindoso ${ }^{1,3}$, Clara

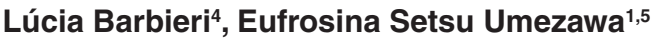

\begin{abstract}
Exoantigens (exo) from Leptomonas seymouri and Crithidia fasciculata were used in an enzyme linked immunosorbent assay (ELISA), showing $100 \%$ reactivity with sera from visceral leishmaniasis (VL) cases, and no reactivity with American tegumentary leishmaniasis (ATL) ones. Our results have indicated that these exoantigens can be applied in the discrimination of VL and ATL cases.
\end{abstract}

KEYWORDS: Leptomonas seymouri. Crithidia fasciculata. Leishmania (Leishmania) infantum chagasi. Exoantigens. Leishmaniasis.

\section{SHORT COMMUNICATION}

Within the Trypanosomatidae family, plant and insect trypanosomatids have been used as laboratory models for biochemistry and molecular biology studies as they share homologous molecules with pathogenic species such as Leishmania spp. and Trypanosoma cruzi, the causative agents of leishmaniasis and Chagas disease, respectively ${ }^{1-4}$. The high degree of conserved antigens between plant and insect trypanosomatids may explain their cross-immunoreactivity with sera from Chagas disease $(\mathrm{CD})^{5-8}$, visceral leishmaniasis $(\mathrm{VL})^{6,9-11}$ and American tegumentary leishmaniasis (ATL) patients ${ }^{6,12}$. To date few studies have investigated this interesting feature of trypanosomatids, the majority being limited to phylogenetic analyses ${ }^{13}$.

Despite the numerous studies on exoantigens of insect and plant trypanosomatids ${ }^{1,3,4,14}$, the immunogenicity of these protozoans and the fact that they can be recognized by anti-Leishmania spp. and anti-T. cruzi antibodies has been overlooked. In contrast, exoantigens of $T$. cruzi $^{15}$, and Leishmania $\operatorname{spp}^{16}$ have been studied, have performed well in the diagnosis of $\mathrm{CD}^{17,18}$, and have also been promising for the diagnosis of $\mathrm{VL}^{19-21}$ and $\mathrm{ATL}^{20-23}$.

In this study, exoantigens from the insect trypanosomatids $L$. seymouri and C. fasciculata were tested by ELISA to evaluate the reactivity of $\operatorname{IgG}$ antibodies from patients with CD, VL and ATL.

Exoantigens from $L$. seymouri (TCC011E) and C. fasciculata (TCC039) were obtained as previously described for excreted-secreted antigens (ESA) of $L$. (L.) infantum chagasi ${ }^{20}$ (MHOM/BR/1972/LD). Briefly, exoantigens from L. seymouri and $C$. fasciculata were recovered from RPMI-1640 medium containing 1-5 x $10^{8}$ cultured parasites $/ \mathrm{mL}$ after incubation for $24 \mathrm{~h}$ at $26^{\circ} \mathrm{C}$ without agitation, and stored in small aliquots at $-40{ }^{\circ} \mathrm{C}$. They were then used without any further purification. None of the exoantigen batches contained tubulin molecules that may have been 
released from the lysed parasites, as attested by the absence of reactivity with a monoclonal anti- $\alpha$ tubulin antibody (data not shown). Trypomastigote excreted-secreted antigens (TESA) of T. cruzi (Y strain) were obtained as described elsewhere ${ }^{17}$. Alkaline extracts (AEs) from L. seymouri, $C$. fasciculata and $L$. (L.) infantum chagasi promastigotas and $T$. cruzi epimastigotes were prepared as previously described ${ }^{6,18,20}$. Briefly, the parasite pellets were solubilized in $0.3 \mathrm{~N} \mathrm{NaOH}$ for $18 \mathrm{~h}$ at $4{ }^{\circ} \mathrm{C}$, neutralized with $0.3 \mathrm{~N} \mathrm{HCl}$ to $\mathrm{pH} 7-8$, and centrifuged at $12,000 \mathrm{~g}$ for $1 \mathrm{~min}$. at $4{ }^{\circ} \mathrm{C}$. The protein concentration of the supernatants was quantified (Macro-bicinchoninic acid protein assay reagent kit; Pierce $\mathrm{Co}$, Rockford, USA) and aliquots were stored at $-20^{\circ} \mathrm{C}$.

ELISAs were performed as previously described ${ }^{6,20}$ using diluted sera 1:200 and incubated with $4 \mu \mathrm{g} / \mathrm{mL}$ of AEs from the parasites analyzed and with $2 \mathrm{mg} / \mathrm{mL}$ of exoantigens from $L$. seymouri and C. fasciculata, and $1 \mathrm{mg} / \mathrm{mL}$ of ESA from $L$. (L.) infantum chagasi and TESA. Serum samples were recorded as positive or negative based on the cut-off values calculated from the receiver operating characteristics (ROC) for sera collected from 20 healthy blood donors from endemic and non-endemic areas of CD and Leishmania spp.

One-way analysis of variance with Bonferroni multiple comparison adjustment was used to compare the mean titers from the evaluated antigens and parasites. The results were considered significant when $p<0.05$ with a $95 \%$ confidence interval. Statistical analyses were performed with the GraphPad Prism 3.0 for Windows (GraphPad Software, USA).

Figure 1 shows the reactivity of serum IgG antibodies according to the antigenic preparation and results were expressed as the absorbance at $492 \mathrm{~nm}\left(\mathrm{Abs}_{492 \mathrm{~nm}}\right)$. Data from ELISA-Exo revealed that molecules released from $L$. seymouri and $C$. fasciculata reacted with all of the sera $(n=30)$ from patients with active VL, living in the State of Piauí, Brazil, whose clinical and diagnostic data had been previously reported ${ }^{24}$, and the reactivity was similar to that obtained with ESA from $L$. (L.) infantum chagasi (Fig. 1A, Table 1), with no statistical difference between the two tests results $(p>0.05)$, while TESA from T. cruzi cross-reacted with only $13 \%$ of the sera from VL patients (Fig. 1A, Table 1). AEs from L. seymouri, C. fasciculata and $L$. (L.) infantum chagasi reacted with $\operatorname{IgG}$ antibodies from $100 \%$ of VL cases, with no statistical difference among them $(p>0.05)$, while AE from T. cruzi reacted with $93 \%$ of VL cases (Fig 1B, Table 1), confirming previously described data ${ }^{6}$.

It is known that antibodies found in VL cases show a high degree of cross-reactivity with antigens of different trypanosome species $^{6,20}$. Indeed, several authors found

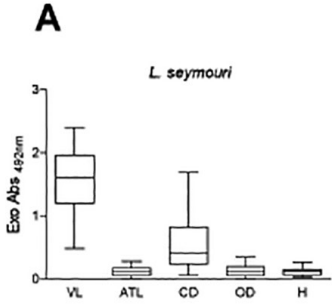

B
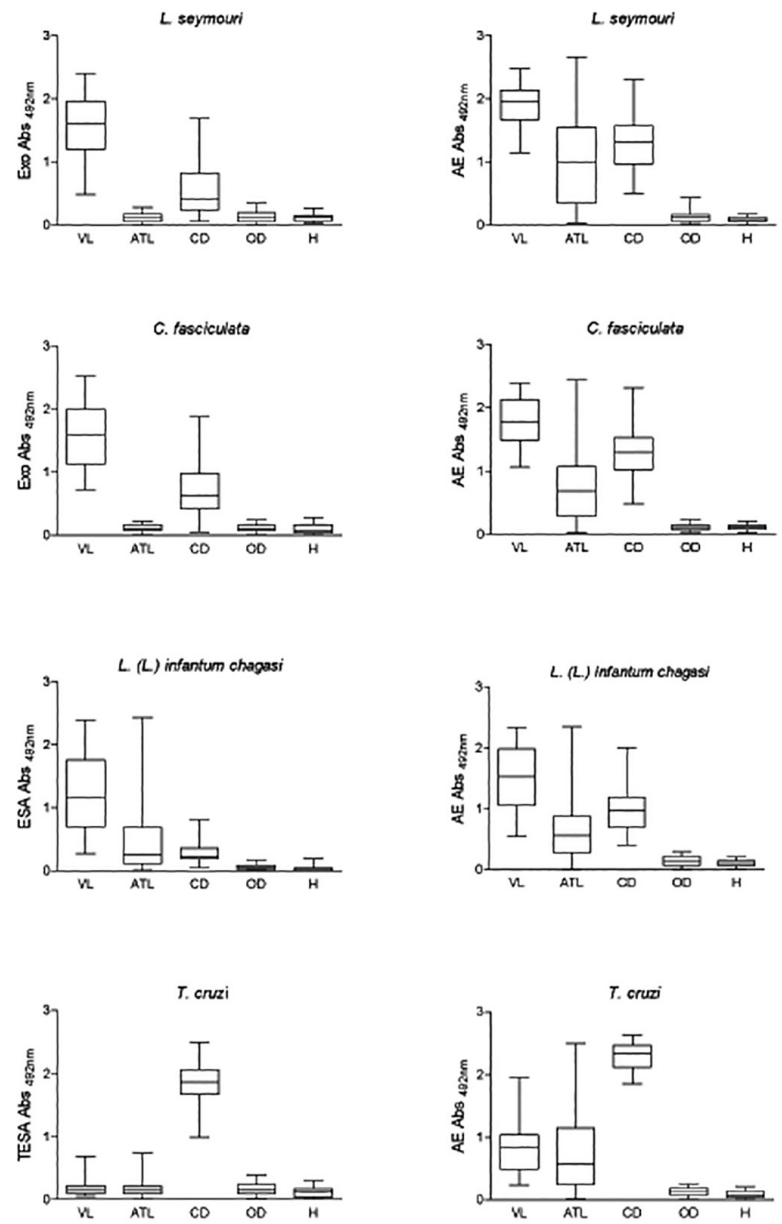

Figure 1 - Box-and-whisker plots of levels of specific IgG antibodies against Exo, ESA, TESA (A) and AE antigens (B) of $L$. seymouri, C. fasciculata, L. (L.) infantum chagasi and $T$. cruzi expressed as the absorbance at $492 \mathrm{~nm}$ (Abs $492 \mathrm{~nm}$ ) in sera from patients with human visceral leishmaniasis (VL), American tegumentary leishmaniasis (ATL), Chagas disease (CD) and other diseases (OD), as well as in sera from healthy individuals $(\mathrm{H})$. The horizontal line inside the box-whisker plot indicates the median.

that serological methods for the detection of VL or ATL cases failed to discriminate between VL and ATL, even with the use of species-specific antigens ${ }^{12,20,25}$. Thirty-two sera from Brazilian ATL patients from the Instituto de Infectologia Emílio Ribas in São Paulo, presenting with clinical diagnosis, as well as a positive Montenegro skin test and identification of the parasites in either skin or mucosal biopsies showed no reactivity with exoantigens from L. seymouri or C. fasciculata, while 53\% of them reacted with ESA from $L$. (L.) infantum chagasi, a significant statistical difference $(\mathrm{p}<0.05)$, and $13 \%$ reacted with TESA from T. cruzi although titers were lower (Fig. 1A, Table 1). ATL sera cross-reacted with AE from L. seymouri (63\%), C. fasciculata $(56 \%)$, L. (L.) infantum chagasi $(66 \%)$ and 
Table 1 - Number of positive cases $(n)$ and percentage of positivity (P\%) of human sera from patients with visceral leishmaniasis (VL), American tegumentary leishmaniasis (ATL), Chagas disease (CD) and other diseases (OD), as well as from healthy individuals $(\mathrm{H})$. Sera were tested by ELISA using exoantigens (Exos), ESA, TESA and alkaline extracts (AEs) of L. seymouri, C. fasciculata, L. (L.) infantum chagasi, and T. cruzi.

\begin{tabular}{lccccccccc}
\hline & \multicolumn{10}{c}{$n(\%)$} \\
\cline { 2 - 10 } & \multicolumn{2}{c}{ L. seymouri } & \multicolumn{2}{c}{ C. fasciculata } & L. (L.) infantum chagasi & \multicolumn{2}{c}{ T. cruzi } \\
\hline Group & $n$ & Exo & AE & Exo & AE & ESA & AE & TESA & AE \\
\hline VL & 30 & $30(100)$ & $30(100)$ & $30(100)$ & $30(100)$ & $30(100)$ & $30(100)$ & $4(13)$ & $28(93)$ \\
ATL & 32 & 0 & $20(63)$ & 0 & $18(56)$ & $17(53)$ & $21(66)$ & $4(13)$ & $19(77)$ \\
CD & 27 & $15(56)$ & $26(96)$ & $17(63)$ & $26(96)$ & $11(41)$ & $27(100)$ & $27(100)$ & $27(100)$ \\
OD & 29 & 0 & 0 & 0 & 0 & 0 & 0 & 0 & 0 \\
H & 20 & 0 & 0 & 0 & 0 & 0 & 0 & 0 & 0 \\
\hline cut off & & 0.38 & 0.66 & 0.50 & 0.64 & 0.23 & 0.38 & 0.36 & 0.34 \\
\hline
\end{tabular}

T. cruzi (77\%), with no statistical difference among them $(p>0.05)$ (Fig 1B, Table 1).

In this study, exoantigens from C. fasciculata and $L$. seymouri did not exhibit antigenic molecules that react with ATL antibodies, however, it was not possible to determine the Leishmania species causing lesions in our casuistic so as to affirm that the results presented herewith could be extended for all species occurring in Brazil. Nonetheless, our results have suggested that these exoantigens may constitute a potential alternative for discriminating between VL and ATL.

Cross-reactivity was evaluated using sera from 27 chronic CD patients whose positivity was confirmed by serology. High reactivity levels were observed with AEs from $L$. seymouri and $C$. fasciculata $(96 \%)$ and $L$. $(L$.) infantum chagasi $(100 \%)$ with no statistical difference among them ( $p>0.05)$, while for T. cruzi $(100 \%)$ higher mean titers $(\mathrm{p}<0.05)$ were detected (Fig 1B, Table 1).

A total of $56 \%$ and $63 \%$ of these sera were reactive to exoantigens from $L$. seymouri and C. fasciculata $(\mathrm{p}>0.05)$; and $41 \%$ with ESA from $L$. ( $L$. ) infantum chagasi $(\mathrm{p}<0.05)$; while reactivity was $100 \%$ with TESA (Fig. 1A, Table 1).

Despite the cross-reactivity with sera from CD patients, the mean ELISA titers using non-pathogenic trypanosomatid antigens were always lower $(\mathrm{p}<0.05)$ when compared to the ones from ELISA using T. cruzi antigens.

As expected, none of the 29 sera from patients with other diseases (OD), as defined by clinical, epidemiological and serological diagnosis (4 with toxoplasmosis, 4 with malaria, 4 with schistosomiasis, 6 with tuberculosis, 5 with autoimmune diseases (presence of antinuclear antibodies), 3 with histoplasmosis and 3 with toxocariasis, or 20 healthy (H) blood donors, showed cross-reactivity with exoantigens, ESA, TESA or AE antigens (Fig. 1A, B; Table 1).

This finding represents an advance in the study of diagnostic techniques for leishmaniasis and it opens up the possibility of using molecules released by $L$. seymouri and C. fasciculata in the ELISA format to develop a rapid, accurate and sensitive diagnostic procedure for differentiating between VL and ATL. Moreover, insect trypanosomatids are non-pathogenic to humans and could be used instead of pathogenic Leishmania species. The ability to differentiate infection caused by dermotropic Leishmania from viscerotropic Leishmania in areas where there is an overlap of these parasites, and also the fact that this antigen could be also applied to seroprevalence studies in non-endemic areas for $T$. cruzi are very exciting. However, future accuracy studies in larger populations must be conducted in order to state the real utility of the tested techniques.

\section{ACKNOWLEDGMENTS}

This study received approval from the Ethical Committee of Human Research of Hospital das Clínicas da Faculdade de Medicina da Universidade de São Paulo, Brazil, under the protocol number $1106 / 08$. This study was part of the academic thesis of Norival Kesper.

\section{FINANCIAL SUPPORT}

This study was supported by grants from LIM48 and LIM49 -HCFMUSP.

\section{REFERENCES}

1. Elias CG, Aor AC, Valle RS, D'Avila-Levy CM, Branquinha MH, Santos AL. Cysteine peptidases from Phytomonas serpens: biochemical and immunological approaches. FEMS Immunol Med Microbiol. 2009;57:247-56. 
2. Etges R. Identification of a surface metalloproteinase on 13 species of Leishmania isolated from humans, Crithidia fasciculata, and Herpetomonas samuelpessoai. Acta Trop. 1992;50:205-17.

3. Jaffe CL, Dwyer DM. Extracellular release of the surface metalloprotease, gp63, from Leishmania and insect trypanosomatids. Parasitol Res. 2003;91:229-37.

4. Santos AL, Soares RM, Alviano CS, Kneipp LF. Heterogeneous production of metallo-type peptidases in parasites belonging to the family Trypanosomatidae. Eur J Protistol. 2008;44:103-13.

5. Breganó JW, Picão RC, Graça VL, Menolli RA, Itow JS, Pinge Filho P, et al. Phytomonas serpens, a tomato parasite, shares antigens with Trypanosoma cruzi that are recognized by human sera and induce protective immunity in mice. FEMS Immunol Med Microbiol. 2003;39:257-64.

6. Ferreira LR, Kesper N, Teixeira MM, Laurenti MD, Barbieri CL, Lindoso JA, et al. New insights about cross-reactive epitopes of six trypanosomatid genera revealed that Crithidia and Leptomonas have antigenic similarity to $L$. $(L$.) chagasi. Acta Trop. 2014; 131:41-6.

7. Lopes JD, Caulada Z, Barbieri CL, Camargo EP. Cross-reactivity between Trypanosoma cruzi and insect trypanosomatids as a basis for the diagnosis of Chagas disease. Am J Trop Med Hyg. 1981;30:1183-8.

8. Monteón VM, Guzmán-Rojas L, Negrete-García C, Rosales-Encina JL, Lopez PA. Serodiagnosis of American trypanosomosis by using nonpathogenic trypanosomatid antigen. J Clin Microbiol.1997;35:3316-9.

9. Hedge EC, Moody AH, Ridley DS. An easily cultured Crithidia sp. as antigen for immunofluorescence for Kala-azar. Trans R Soc Trop Med Hyg. 1978;72:445.

10. Lopez-Bréa M. Diagnóstico serológico por immunofluorescência indirecta de la leishmaniasis viscreal mediante la utilizacíon del protozoo Crithidia sp. como antígeno. Rev San Hyg Public. 1979;53:1109-15.

11. Martinkovic F, Marinculic A. Antibodies against Leishmania crossreact with Crithidia luciliae: indirect immunofluorescence and Dot-ELISA study in dogs. Parasitol Res. 2006;98:378-80.

12. Gonçalves CC, Reiche EM, De Abreu Filho BA, Silveira TG, Felizardo TC, Maia KR, et al. Evaluation of antigens from various Leishmania species in a Western blot for diagnosis of American tegumentary leishmaniasis. Am J Trop Med Hyg. 2002;66:91-102.

13. Teixeira MM, Borghesan TC, Ferreira RC, Santos MA, Takata CS, Campaner M, et al. Phylogenetic validation of the genera Angomonas and Strigomonas of trypanosomatids harboring bacterial endosymbionts with the description of new species of trypanosomatids and of proteobacterial symbionts. Protist. 2011;162:503-24.

14. Santos AL, Branquinha MH, D'Avila-Levy CM. The ubiquitous gp63-like metalloprotease from lower trypanosomatids: in the search for a function. An Acad Bras Cienc. 2006;78:687-714.
15. Gonçalves MF, Umezawa ES, Katzin AM, de Souza W, Alves MJ, Zingales B, et al. Trypanosoma cruzi: shedding of surface antigens as membrane vesicles. Exp Parasitol. 1991;72:43-53.

16. DebRoy S, Keenan AB, Ueno N, Jeronimo SM, Donelson JE, Wilson ME. Leishmania infantum chagasi: a genome-based approach to identification of excreted/secreted proteins. Exp Parasitol. 2010;126:582-91.

17. Umezawa ES, Nascimento MS, Kesper N Jr, Coura JR, Borges-Pereira J, Junqueira ACV, et al. Immunoblot assay using excreted-secreted antigens of Trypanosoma cruzi in serodiagnosis of congenital, acute and chronic Chagas'disease. J Clin Microbiol. 1996;34:2143-7.

18. Umezawa ES, Nascimento MS, Stolf AM. Enzyme-linked immunosorbent assay with Trypanosoma cruzi excretedsecreted antigens (TESA-ELISA) for serodiagnosis of acute and chronic Chagas disease. Diagn Microbiol Infect Dis. 2001;39:169-76.

19. Martin SK, Thuita-Harun L, Adoyo-Adoyo M, Wasunna KM. A diagnostic ELISA for visceral leishmaniasis, based on antigen from media conditioned by Leishmania donovani promastigotes. Ann Trop Med Parasitol. 1998;92:571-7.

20. Pinedo-Cancino V, Kesper N, Barbiéri CL, Lindoso JA, Umezawa, ES. The efficacy of $L$. (L.) chagasi excreted-secreted antigens (ESAs) for visceral leishmaniasis diagnosis is due to low levels of cross-reactivity. Am J Trop Med Hyg. 2013;88:559-65.

21. Ryan JR, Smithyman AM, Rajasekariah GH, Hochberg L, Stiteler JM, Martin SK. Enzyme-linked immunosorbent assay based on soluble promastigote antigen detects immunoglobulin $\mathrm{M}$ (IgM) and IgG antibodies in sera from cases of visceral and cutaneous leishmaniasis. J Clin Microbiol. 2002;40:1037-43.

22. Romero LI, Paz HM, Ortega-Barría E, Bayard V, Hochberg LP, Collins KM, et al. Evaluation of serological assays based on a novel excreted antigen preparation for the diagnosis of cutaneous leishmaniasis in Panama. J Microbiol Methods. 2004;57:391-7.

23. Soares KA, Urdapilleta AA, Santos GM, Carneiro AL, Gomes CM, Roselino AM, et al. Field validation of a Leishmania (Leishmania) mexicana exo-antigens ELISA for diagnosing tegumentary leishmaniasis in regions of Leishmania (Viannia) predominance. Braz J Infect Dis. 2015;19:302-7.

24. De Souza Dias, S, da Costa Pinheiro PH, Katz S, dos Santos MR, Barbiéri CL. A recombinant cysteine proteinase from Leishmania (Leishmania) chagasi suitable for serodiagnosis of American visceral leishmaniasis. Am J Trop Med Hyg. 2005;72:126-32.

25. Goto H, Lindoso JA. Current diagnosis and treatment of cutaneous and mucocutaneous leishmaniasis. Expert Rev Anti Infect Ther. 2010;8:419-33. 